\title{
OS TEXTOS FICCIONAIS VOLTADOS PARA A CRIANÇA E O JOVEM E O ENSINO DA literatura: uma leitura de “Tanta Tinta”, de Cecília Meireles
}

\author{
Aroldo José Abreu Pinto*
}

\section{Resumo}

Neste trabalho, o intuito é refletir sobre algumas noçôes que normalmente são disseminadas sobre a leitura e o ensino da literatura em sala de aula com a chamada literatura infantojuvenil. Procuramos, mais pontualmente, destacar como grande parte dos textos ficcionais contemporâneos voltados ao público jovem traz em si um embate de representaçóes que exige um leitor participante no processo de leitura e um educador preparado para sua observação, sob o risco do texto não se concretizar em sua totalidade no ato da leitura, pois eliminam premissas básicas contidas na literatura de massa.

Palavras-chave: leitura, literatura infanto-juvenil, tensão dialética, Cecília Meireles, esteticidade.

The fictional texts oriented to youngsters and adolescents and the teaching of literature in the classroom: a reading of “ Tanta Tinta “, from Cecília Meireles

\section{Abstract}

Our goals in this study are to establish a reflection on some notions that are normally spread about the reading process, as well as the teaching/learning methods concerned to literature inside the classroom when the focus is the genre written for children and teenagers. More specifically, we tried to highlight how some of the contemporary fictional texts published for youngsters carry within themselves an impact of representations, which demand from the receiver a major participation on the reading process, besides an educator who is aware of a previous preparation in order to make an analysis of what is being interpreted or the message will not be completely understood when decoding the paragraphs because of its basic premises.

KEY WORDS: reading, children's literature, dialectical tension, Cecília Meireles, estheticity.

\section{CONSIDERAÇÓES GERAIS SOBRE A LEITURA E O ENSINO DA LITERATURA NOS} TEXTOS FICCIONAIS VOLTADOS ÀS CRIANÇAS E JOVENS

Não sei como aprendi a ler; só me lembro das minhas primeiras leituras.

Rousseau

* Professor da Universidade do Estado de Mato Grosso - UNEMAT. Doutor em Letras pela Faculdade de Ciências e Letras de Assis - UNESP. E-mail: aroldoabreu@uol.com.br. 


\section{Revista Solta a Voz, v. 19, n. 1}

A primeira questão que geralmente norteia as reflexóes sobre a leitura e o ensino da literatura para crianças e jovens é a discussão que se faz sobre uma possível função ou funções da literatura. Em nome dessa discussão acerca do assunto, inclusive, muitos equívocos são cometidos, pois, se em relação à literatura "para adultos" essa polêmica já exige debates mais sistematizados, vislumbre-se as discussóes em relação à voltada para a criança e o jovem que recebem desde a sua concepção o rótulo/denominação de "paradidáticos". Aqui recorremos ao crítico e professor Antonio Candido (1972) que nos fala de pelo menos duas de suas funçóes: a psicológica e a função formativa.

Sobre a função psicológica, Candido (1972) nos diz que, quando pensamos em seu papel, a primeira coisa que devemos ter em mente é que, se há uma função na literatura é, em um primeiro momento, a de satisfazer a uma necessidade de ficção e fantasia que é própria do homem, tanto individualmente, quanto em grupo, tanto no homem primitivo, quanto no homem civilizado, tanto na criança como no adulto, no instruído ou no analfabeto.

Um exemplo de que isso é um fato a ser considerado pode ser observado nas manifestaçóes mais básicas e espontâneas de ficção e fantasia: a piada ou o trocadilho, pois, se contarmos um chiste como aquele do Joãozinho, do papagaio etc. ainda não estamos no âmbito da literatura nos moldes tradicionais e canonizados pela crítica especializada, mas certamente estamos satisfazendo a essas necessidades primárias. Vejamos uma piada e um quadrinho como exemplo:

Joãozinho estava brincando de esconder e resolveu esconder-se no armário. Como estava escurinho, acabou pegando no sono. Ficou dormindo dentro do armário até ser acordado pelo amante de sua mãe, que se escondeu lá dentro quando o marido dela chegou mais cedo.

Joãozinho resolve puxar um papo...

- Tá escuro aqui, né?

- É... responde o homem meio sem graça.

- Quer comprar uma bola de futebol?

- Não obrigado...

- Tem certeza? Diz Joãozinho, aumentando o tom da voz.

- Tá bom, por quanto?

-500 Reais!

- O quêt?? 500 Reais!!! Tá bom, eu pago, afinal não estou em condições de reclamar... 
- Daí a pouco o garoto pergunta:

- Tá escuro aqui né?...

- Tá, mas vê se fica quietinho tá bom? Responde o homem...

- Quer comprar uma camisa do Flamengo? Diz o Joãozinho.

- ... Quanto?

- 500 Reais!

- PQP tudo isso? Tá bom, toma o dinheiro...

- No fim de semana, o pai do garoto o convida para jogar uma pelada e o garoto dispara:

- Ih pai não vai dar. Eu vendi a minha bola e a minha camisa...

- Vendeu? Por quanto?

- Mil Reais.

- Mil Reais??? Mas que sacanagem! Vá já se confessar com o padre agora! Isso foi uma extorsão!!!

Chegando na igreja, Joãozinho entrou no confessionário. Quando padre chegou foi logo falando:

- Oi seu padre... tá escuro aqui, né?

- Ah, não vem com essa história não Joãozinho, que hoje não vou comprar merda nenhuma!!!

(Disponível em: <http://www.ocorreionews.com.br/index.php?news=37>. Acesso em: 13 maio 2008)

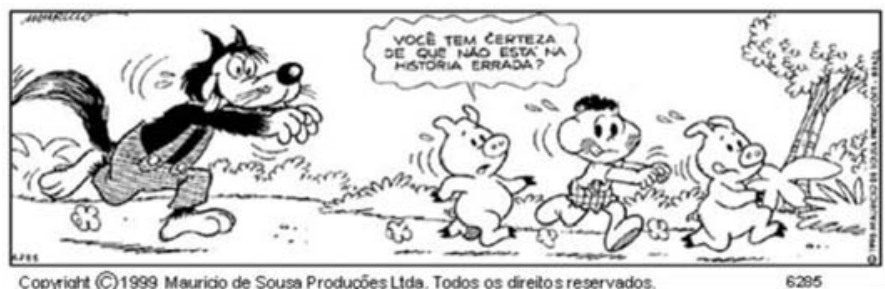

Note-se que fica fácil haver uma identificação imediata do leitor com os objetos acima, uma vez que tanto os signos lingüísticos quanto os visuais dados são organizados de tal forma que geram o riso ou, pelo menos, suscitam a expectativa no leitor, buscando satisfazer suas necessidades imediatas de ficção e fantasia.

Ora, por que estamos destacando isso? Porque nós, professores e educadores, estamos sempre procurando dar uma função ou funçóes ao texto ficcional quando, na verdade, precisaríamos lembrar que o que deveríamos buscar é, antes de tudo, o aspecto lúdico, o prazer, o livro como um brinquedo, um jogo etc. Mas aí vem uma segunda pergunta: 


\section{Revista Solta a Voz, v. 19, n. 1}

o texto, a imagem, enfim, os signos de que nos valemos não ensinam naturalmente? Neste caso, buscamos respaldo na segunda função de que nos fala Candido (1972): a capacidade que a literatura tem de contribuir para a formação da nossa personalidade. $\mathrm{O}$ próprio estudioso e crítico da literatura brasileira nos pergunta: existe uma função formativa do tipo educacional na literatura? E ele mesmo responde que sim, mas não do ponto de vista estritamente pedagógico como muitos querem fazer pensar, pois, muito além de formar, ensinar, educar segundo a pedagogia oficial que a vê como veículo de divulgação do verdadeiro, do bom e do belo, segundo as suas concepçóes e não as da criança e do jovem, a literatura nos "humanizaria" conscientemente ou inconscientemente. Em outras palavras, ela humaniza porque nos faz viver as sensaçôes ali sugeridas e não porque este ou aquele autor ou este ou aquele educador propositadamente apontou essas questóes e usou isso como forma de incutir ensinamentos. Tomemos dois poemas como exemplo desta capacidade de humanizar sem necessariamente partir para o discurso engajado, utilitário, panfletário que norteia grande parte dos textos voltados para a criança e o jovem.

No poema "Perguntas e respostas cretinas", adaptado de Segredinhos de amor, de Elias José (1991, p. 20-21), podemos observar como o autor aborda naturalmente uma questão considerada tabu para as crianças: a representação da morte:

\section{Perguntas e respostas cretinas}

Você conhece o João?

Aquele que te deu um bofetão?

Você conhece o Zé?

Aquele que pegou no seu pé?

Você conhece a Mara?

Aquela que tirou sarro da sua cara?

Você conhece a Esmeralda?

Aquela que trocou sua fralda?

Você conhece a Marieta?

Aquela que lhe fez careta?

Você conhece o Vieira?

Aquele que fez sua caveira? 
Você conhece o Chico?

Aquele que lhe deu um penico?

Você conhece o Joaquim?

Conheço, mas ele... chegou ao fim!

Atentemos para o desfecho do poema: "Você conhece o Joaquim? / Conheço, mas ele... chegou ao fim!". Podemos observar que o tema/assunto é a morte, mas esta é trazida após um jogo de perguntas e respostas corriqueiras, comum entre as crianças. Portanto, a questão da morte surge de maneira natural. Neste caso, o texto "humaniza" porque nos faz viver as sensações ali sugeridas de maneira direta, mas natural, sem verdades prontas e absolutas. Não se alimentam os tabus.

\section{Uma leitura de "Tanta Tinta”, de Cecília Meireles}

Outro exemplo que podemos tomar para reflexão é o poema "Tanta Tinta”, de Cecília Meireles, publicada na obra Ou isto ou aquilo (1987, p. 27):

\section{Tanta Tinta}

Ah! menina tonta, toda suja de tinta mal o sol desponta!

(Sentou-se na ponte, muita desatenta...

E agora se espanta:

Quem é que a ponte pinta com tanta tinta?...)

A ponte aponta e se desaponta.

A tontinha tenta limpar a tinta, ponto por ponto e pinta por pinta...

Ah! a menina tonta!

Não viu a tinta da ponte! 
Conforme afirma José Carlos Garbuglio (apud Pinto, 1999, p. 9) "a arte é um jogo que brinca e diverte. Sua eficácia depende muito da habilidade do criador em dispor das palavras e empenhar o leitor na sua aventura”. Portanto, em um plano bastante amplo, poderíamos afirmar que o poema dá conta de uma passagem banal, corriqueira, satisfazendo nossas necessidades básicas de ficção e fantasia. Isto é garantido graças ao aparente retrato de algo corriqueiro: uma menina desatenta, ao passar por uma ponte, senta-se nela. Somente depois que já se sujou toda de tinta é que percebe que a ponte foi recém-pintada, mas aí já é tarde. Tenta, mas não consegue mais limpar a tinta. Acrescente-se a isso as sonoridades: "Ah! menina tonta, / toda suja de tinta"; as rimas: "tonta" / "desponta"; as aliteraçôes e assonâncias (repetição consoantes e vogais): "Sentou-se na ponte, / muita desatenta... / E agora se espanta: / Quem é que a ponte pinta / com tanta tinta?...)"; e a repetiçáo de palavras com sons semelhantes: "A ponte aponta / e se desaponta. / A tontinha tenta / limpar a tinta, / ponto por ponto / e pinta por pinta...”.

Devemos sempre lembrar que um dos fatores mais fortemente considerados pelo leitor no momento da leitura é, geralmente, o conteúdo representado. Porém, o educador necessita ir muito além dessa premissa básica. Deve dar conta, também, do modo de representação e suas implicaçóes. Desse modo, o texto de Cecília Meireles deve ser tomado de maneira mais acurada.

Numa leitura imaginável, poderíamos tomar o poema como a representação da transição da infância para a juventude, o período da puberdade. No Novo Dicionário Aurélio da Língua Portuguesa (2004), puberdade é especificada como " 1 . Conjunto das transformaçôes psicofisiológicas ligadas à maturação sexual que traduzem a passagem progressiva da infância à adolescência”.

Tomemos, inicialmente, a estrutura do poema. Dividido em três estrofes, podemos claramente perceber, por extensão, três momentos:

10 MOMENTO > (três versos) $=$ transição da infância para a préadolescência: "Ah! menina tonta, / toda suja de tinta / mal o sol desponta!".

$2^{\circ}$ MOMENTO $>$ (cinco versos $)=$ transição da pré-adolescência para a adolescência. Época dos "parênteses", das incertezas: "(Sentou-se na ponte, / muita desatenta... / E agora se espanta: / Quem é que a ponte pinta / com tanta tinta?...)". 
$3^{\circ} \mathrm{MOMENTO}>$ (oito versos) $=$ transição adolescência para a juventude: "A ponte aponta / e se desaponta. / A tontinha tenta / limpar a tinta, / ponto por ponto / e pinta por pinta... / Ah! a menina tonta! / Não viu a tinta da ponte!".

Total $>($ dezesseis versos $)=$ dezesseis anos.

Esquematicamente:

\begin{tabular}{|c|c|}
\hline $\begin{array}{l}1^{0} \text { MOMENTO > } \\
\text { (três versos) = transiçã̃o } \\
\text { Infância/pré-adolescência }\end{array}$ & $\begin{array}{l}\text { Ah! menina tonta, } \\
\text { toda suja de tinta } \\
\text { mal o sol desponta! }\end{array}$ \\
\hline $2^{\circ}$ MOMENTO > & (Sentou-se na ponte, \\
\hline (cinco versos) $=$ transiçăo & E agora se espanta: \\
\hline pré-adolescência/adolescência. & Quem é que a ponte pinta \\
\hline $\begin{array}{l}\text { Época dos "parênteses", das } \\
\text { incertezas }\end{array}$ & com tanta tinta?...) \\
\hline $3^{\circ}$ MOMENTO > & A ponte aponta \\
\hline $\begin{array}{l}\text { (oito versos) = transição } \\
\text { adolescência/juventude }\end{array}$ & $\begin{array}{l}\text { e se desaponta. } \\
\text { A tontinha tenta } \\
\text { limpar a tinta, }\end{array}$ \\
\hline Total & $\begin{array}{l}\text { ponto por ponto } \\
\text { e pinta por pinta. }\end{array}$ \\
\hline (dezesseis versos) $=$ & Ah! a menina tonta! \\
\hline dezesseis anos & Não viu a tinta da ponte! \\
\hline
\end{tabular}

Considerando-se que o título da obra em que foi publicado o poema "Tanta Tinta" é Ou isto ou aquilo, poderíamos ampliar ainda mais o leque de reflexóes para dar conta da leitura que estamos propondo: a representação da transição da infância para a juventude, pois o "ISTO" (próximo) parece estar nitidamente em correspondência com o "AQUILO" (mais distante). Em outras palavras, na camada mais aparente e mais imediata temos o plano do hoje, do agora, da menina ainda com atitudes de criança, enquanto que no plano simbólico temos o plano do amanhã, do que está por acontecer com a menina que está em uma fase de transição para tornar-se mulher.

Em uma correspondência imediata e esquemática desses dois planos, teríamos: 


\section{Ou isto ou aquilo}

\begin{tabular}{|c|c|c|}
\hline \multicolumn{2}{|c|}{$\begin{array}{l}\text { "ISTO" (próximo) } \\
\text { Camada mais aparente } \\
\text { Plano do hojelagora }\end{array}$} & $\begin{array}{l}\text { "AQUILO" (mais distante) } \\
\text { Plano dos símbolos } \\
\text { Plano do amanhã do } \\
\text { que está por vir }\end{array}$ \\
\hline "menina tonta" & $\mathrm{x}$ & mas o "sol desponta" \\
\hline “ponte" & $\mathrm{x}$ & rito de passagem \\
\hline "tinta" e "sol" & $\mathrm{X}$ & marca visível do rito \\
\hline "limpar a tinta" & $x$ & entender o rito \\
\hline "pinta por pinta" & $\mathrm{x}$ & novas situações/fatos \\
\hline "Não viu a tinta" & $\mathrm{x}$ & não viu o tempo passar \\
\hline
\end{tabular}

Podemos considerar, ainda:

\section{Ou isto ou aquilo}

Camada mais aparente Plano dos símbolos

"agora se espanta" X estranhamento com a nova situação

"Quem é que a ponte $X$ pinta com tanta tinta?" a menina ou a mulher que nasce?

"parênteses" X cercada de incertezas

"tontinha" X diminutivo de "tonta", mas também zonza, atordoada pela nova situação

"Ah! Menina tonta" X eu lírico "experiente", distanciado que revela o quão comum é tal situação 
Glória Maria Fialho Pondé (1983, p. 98) afiança que

Cecília Meireles, em seu poema Ou isto ou aquilo, dá um tratamento literário à poesia infantil e demonstra um profundo conhecimento de sua lógica. Nele, a conjunção alternativa náo exclui, mas aproxima as oposiçóes, colocando-as lado a lado, de modo que, ao final, elas se anulam enquanto opçôes e passam a construir um todo, com elementos equivalentes que se somam.

Cabe ao educador, portanto, questionar de que forma deve abordar os textos ficcionais para dar conta, como já dito, do modo de representação e das implicaçóes contidas em um texto ficcional, além do conteúdo. Isso nos leva a uma nova reflexão: devemos tomá-lo como ponto de partida e ponto de chegada do nosso trabalho em sala de aula, ou seja, nós devemos partir sempre do resultado, do que está contido na obra, e não utilizá-la apenas como estímulo ou condicionamento para outras atividades. A importância de uma obra quase nunca é devida à circunstância de exprimir um aspecto da realidade, social ou individual, mas à maneira pela qual o autor o faz (Candido, 1969).

Estamos destacando isso porque, como vimos, poemas como "Tanta Tinta”, de Cecília Meireles, tal como grande parte dos textos ficcionais contemporâneos voltados ao público das séries iniciais do ensino médio, trazem em si um embate de representaçóes que exige um leitor participante do processo de observação do mesmo, sob o risco deste não se concretizar em sua totalidade no ato da leitura. Ademais, eliminam uma premissa básica da literatura de massa, a exacerbação de uma visão maniqueísta da realidade, e optam pelo trabalho estético, exigindo também um educador atento e preparado para trabalhar com esses novos parâmetros.

Em outras palavras, nós, educadores, temos que estar preparados para respeitar este caráter humanizador presente em muitos textos voltados para o público jovem. Até os anos 70 do século passado, tínhamos, com exceção de Monteiro Lobato, poucos autores que assumiam esse ponto de vista emancipatório, tanto na constituição da "camada mais aparente" do texto, ou seja, no que é mais facilmente apreensível pelo leitor "envolvido" e que pode ser detalhado sem o apelo a grandes recursos de teorização, quanto nos aspectos obtidos mediante a problematização e a interpretaçáo de dados e informaçóes sobre o conjunto da obra, que devem fazer parte dos instrumentos do professor em sala de aula. 


\section{Revista Solta a Voz, v. 19, n. 1}

\section{EM BUSCA DE SÍNTESE}

Não há dúvida de que devemos observar de que maneira a narrativa se constitui a partir da sociedade ou do ser, mas muito mais importante é observar como um escritor articula o texto, gerando "um mundo novo, cujas leis fazem sentir melhor a realidade originária" (Candido, 1993, p. 10), como em "Tanta Tinta”, de Cecília Meireles.

Se até a década de 1970 tínhamos, por assim dizer, uma "inferioridade" literária de obras voltadas ao público jovem em relação principalmente à qualidade, hoje a situação mudou e temos tanto quantidade quanto qualidade. Infelizmente, voltamos a afirmar que geralmente nós, educadores, é que não estamos preparados para o trabalho com o texto humanizador/emancipatório.

Para melhor sistematizar a questão dos textos emancipatórios recorremos a Zilberman (1981), em A literatura infantil na escola, e às considerações sobre o ensino da literatura tomadas do crítico alemão Hans Kügler, em um texto com o título de Literatura e Comunicação, traduzido por Fantinati (1990). Estes autores destacam, resumidamente, que os textos contemporâneos regidos por um conteúdo estético/emancipatório criam um mundo em que o plano do enunciado é negado pelo plano da enunciação, ou seja, o receptor é levado a observar e a acompanhar uma situação, mas, em seguida, o texto reflete justamente o oposto. É como se o narrador negasse justamente para confirmar. Entre o narrado - o que parece ser - e o que efetivamente se diz, há uma lacuna que deve ser preenchida por um leitor mais atento. $\mathrm{O}$ escritor coloca em atividade a capacidade de ponderação do leitor, por meio do choque de representaçóes, visando despertar sua capacidade intelectiva. Entre as imagens criadas, ficam em aberto para o leitor muitos fatos, ou seja, a estrutura do texto ficcional está calcado nessa atribuição de sentidos à mensagem para muito além dos sentidos previstos.

Para chegar a esse efeito, o escritor se utiliza de muitos recursos, mas os mais característicos são a simulação e a contradição, pois introduzem um jogo permanente entre o sentido e o náo-sentido. Em muitos textos contemporâneos, o contexto acaba ampliando os significados e problematizando uma certa visão do mundo para a percepção do leitor.

Maria da Glória Bordini (1982), em comentário feito ao trabalho do cronista Luís Fernando Veríssimo, na obra $O$ gigolô das palavras, des- 
taca bem essa questão que também, nos parece, se manifesta na literatura infanto-juvenil.

Bordini (1982, p. 99) destaca que Luis Fernando Veríssimo é um "sujeito traiçoeiro", pois "quando se compara a receita com o prato que ele serve, lá se escapa o mestre-cuca com algum segredo que nos sonegou e ficamos sem entender o que está acontecendo". Antes de mais nada, Luis Fernando Veríssimo é um "sábio despistador" que, além de "seu show de ilusionismo", acredita "existir, acima das palavras que todos conhecem e usam, uma forma de organizá-las, de mexer com seu sentido comum, de modo que se submetam as suas idéias sem protestos" (idem, p. 102), brincando justamente com a realidade e a linguagem.

Em sala de aula, portanto, seja em relação à literatura infanto-juvenil, seja em gêneros como a crônica, conforme destacado acima, temos que estar atentos para a tensáo entre o que é dito e o que se espera que seria dito; ou entre o que se diz e o que é silenciado e precisa ser decifrado.

Solicitando do receptor inicialmente uma postura empática e efetivamente identificadora com o texto e, em um segundo momento, uma atitude atuante e interveniente no ato da leitura, como já destacamos no processo de reflexão até aqui empreendido com o poema "Tanta Tinta", de Cecília Meireles, alguns textos da literatura infanto-juvenil contemporâneos ganharam em força comunicativa referencial e estética.

Para encerrar, recorremos novamente à citação de Garbuglio (apud Pinto, 1999, p. 9): "A arte é um jogo que brinca e diverte. Sua eficácia depende muito da habilidade do criador em dispor das palavras e empenhar o leitor na sua aventura”. Analogamente a essa nota, diríamos: a literatura infanto-juvenil é um jogo que brinca e diverte, mas a sua eficácia depende muito da habilidade do educador em reconhecer, nas palavras do criador do texto ficcional, o caráter humanizador que toda literatura possui e, assim, estar preparado para esse trabalho, incentivando a leitura.

\section{REFERÊNCIAS}

BORDINI, M. da G. Na pista do Gigolô das palavras. In: VERÍSSIMO, L. F. O Gigolô das palavras. Porto Alegre: L\&PM Editores, 1982. p. 99106. (Coleção Novaleitura, v. 8).

CANDIDO, A. A literatura e a formação do homem. Ciência e Cultura, São Paulo, v. 24, n. 9, p. 806-809, set. 1972. 
CANDIDO, A. Formação da Literatura Brasileira: momentos decisivos. 4. ed. São Paulo: Martins Fontes, 1969. v. 1. . O discurso e a cidade. In: . O Discurso e a Cidade. São Paulo: Duas Cidades, 1993. p. 19-152.

FANTINATI, C. E. Sobre o ensino da literatura: mini-antologia de textos teóricos. São Paulo: UNESP/Assis, 1990. [mimeo]

FERREIRA, A. B. de H. Novo Dicionário Aurélio da Lingua Portuguesa. 3. ed. Curitiba: Editora Positivo, 2004.

JOSÉ, E. Segredinhos de amor. São Paulo: Moderna, 1991.

MEIRELES, C. Ou isto ou aquilo. Rio de Janeiro: Nova Fronteira, 1987.

PIADAS DO DIA. Jornal O CorreioNews. 10 maio 2008. Disponível em: <http://www.ocorreionews.com.br/index.php?news=37>. Acesso em: 13 maio 2008.

PINTO, A. J. A. Literatura descalça: a narrativa para jovens de Ricardo Ramos. São Paulo: Arte e Ciência/Assis: ANEP, 1999.

PONDÉ, G. M. F. Poesia para crianças: a mágica da eterna infância. In: KHEDÉ, S. S. (Org.). Literatura Infanto-juvenil: um gênero polêmico. Petrópolis: Vozes, 1983. p. 92-103.

ZILBERMAM, R. A literatura infantil na escola. São Paulo: Global, 1981.

Recebido em: 21 nov. 2007 Aceito em: 21 fev. 2008 